\title{
Design of Sustainable Product from Carbon Tax Perspective
}

\author{
Shuihua Han and Yue Jiang* \\ School of Management, Xiamen University, 361005 Fujian China \\ jiangyuehxg@126.com
}

\begin{abstract}
With the growing concern of carbon emissions, corporations are facing new challenges about carbon management in the design of sustainable product. This paper integrates carbon tax considerations into the traditional design of product. Two game models in the case of information asymmetry and information symmetry are developed for the design of sustainable product to analyze the impact of carbon tax on the optimal product output, the equilibrium price and the profit. We also analyze the impact of information symmetry and information asymmetry on the optimal product output, the equilibrium price and profit in this paper.
\end{abstract}

Key words: Design of sustainable product; carbon tax; information asymmetry; information symmetry

\section{Introduction}

In recent years, global warming attracts more and more attention, which is the first of the top ten global environmental issues. Global average temperature rising, global warming has become an indisputable fact [1]. The scientific community, industry and government of different countries have realized that the carbon emission from human activity is the main cause of global climate change. Carbon tax is considered as one of the most efficiency economic instruments to reduce carbon emissions, has received more and more attention and been implemented in many countries.

Corporations are facing new challenges with the carbon tax imposed, carbon tax imposed by Government will inevitably lead to the increasing of production and operating cost. For corporation there are two methods to maintain its profit, one is increasing the price of product, the other is improving the sustainable level to reduce carbon emissions. But increasing the price will lead to the loss of customers, so improving the sustainable level of product is a better method [2]. But improving the sustainable level and reducing carbon emissions need to change the original production technology and production processes, these changes will bring the cost rising, so how to choose their products sustainable levels is crucial for corporation. How to adjust the design of sustainable product with the consideration of carbon tax is discussed in this paper, two game models in the case of information asymmetry and information symmetry are developed for the design of sustainable product. How the optimal product output, the equilibrium price and the profit change with the increasing or decreasing of the carbon tax is analyzed in this paper. We also analyze the impact of information symmetry and information asymmetry on the optimal product output, the equilibrium price and profit.

This paper is organized as follows. After this introductory section, the relevant literature is reviewed and summarized. Section 3 is about the model development, in this section two game models about the design of sustainable product in the case of information asymmetry and information symmetry are developed for the design of sustainable product. Section 4 focuses on the comparing and analyzing about the two proposed models. The conclusions are given in the final section. 


\section{Literature Review}

Our paper is positioned between two main streams of literature. The first is related to the carbon tax, the second relates to the design of sustainable product design.

Carbon tax is an effective method to reduce the carbon emission and moderate climate climate change[3]. Nordhaus, Nakata and Lamont analyze the impact of carbon tax on the carbon emission reduction, although they set different tax rates, but the results have consistently shown that carbon tax have significant effects on carbon emissions reduction [4-5]. Gerbelová $\mathrm{H}$ indicates that carbon tax is more flexible and dynamic in response to new information, and it is a potentially cost effective option for reducing carbon emissions [6]. Because carbon tax has an important role on reducing the carbon emission, so currently, carbon tax policies or equivalent measures have been implemented in several countries, such as France, Denmark, Norway, and Switzerland have launched carbon tax policies in their domestic market, so as to enhance their measures in control carbon emission.

On the steam of the design of sustainable product design, Pujari studies the key point of environment factor in the new product development [7]. Rehfeld researches the relationship between sustainable product design and environmental group [8]. Some researches focus on micro-economic analyses of different sustainable design practices, such as Chen analyzes the design of sustainable product under different strategic and regulatory settings [9]. Calcott and Walls compare the impact of different policy instruments on the design of sustainable product [10]. Atasu and Souza investigate the impact of product recovery on design quality choices [11]. Fullerton and $\mathrm{Wu}$, Atasuet also contribute to this field [12-13]. The other papers focus on how to implement the sustainable product in practice. Handfield proposes a comprehensive conceptual framework with detailed implementation processes for the design of sustainable product that include environmental objectives, design processes, and outcome evaluation [14]. Graedel and Allenby identify a number of practical approaches to sustainable product design decisions [15]. Fiksel uses case studies from major corporations to give details about the main implementation steps for the design of sustainable product [16].

Different from exiting paper, we integrates carbon tax considerations into the traditional design of product, analyze how to decide the sustainable level of the sustainable product when carbon tax imposed by the government in the case of information asymmetry and information symmetry and the impact of carbon tax on the decision of Corporation 1 and Corporation 2. We also analyze the impact of information symmetry and information asymmetry on the optimal product output, the equilibrium price and profit in this paper.

\section{Model Development}

\subsection{Model Description}

We assume that there are two corporations producing the same product, they are Corporation 1 and Corporation 2, the unit production cost of Corporation 1 and Corporation 2 is $C_{1}$ and $C_{2}$, the unit carbon emission of Corporation 1 and Corporation 2 is $E_{1}$ and $E_{2}$. We also assume that the unit product cost and carbon emission of Corporation 1 and Corporation 2 are linearity correlation to the sustainable level . The unit cost is positively linearly related the sustainable level, that is the unit production cost increases with the increasing the sustainable level; the unit carbon emission is negatively linearly related the sustainable level, that is the unit carbon emission decreases with the increasing of sustainable level. Equation 1 and Equation 2 show the relation between production cost, carbon emission and the sustainable level. 


$$
\begin{gathered}
C_{1}=\alpha_{1} \tau_{1}+\beta_{1}, C_{2}=\alpha_{2} \tau_{2}+\beta_{2}, \alpha_{1}, \alpha_{2}, \beta_{1}, \beta_{2}>0 \\
E_{1}=-\gamma_{1} \tau_{1}+\delta_{1}, E_{2}=-\gamma_{2} \tau_{2}+\delta_{2}, 0<\gamma_{1}<\frac{\delta_{1}}{\tau_{1}}, 0<\gamma_{2}<\frac{\delta_{2}}{\tau_{2}}, \delta_{1}>0, \delta_{2}>0
\end{gathered}
$$

The product output of Corporation 1 and Corporation 2 is $Q_{1}$ and $Q_{2}$, the inverse demand function of this product in the market is $P=A-Q_{1}-Q_{2}$, we also assume that carbon tax is $t$. The details of related parameter is shown in Table1.

\begin{tabular}{|c|c|}
\hline$\tau_{1}$ & The sustainable level of product from Corporation 1 \\
\hline$\tau_{2}$ & The sustainable level of product from Corporation 2 \\
\hline$\tau_{1}^{\prime}$ & $\begin{array}{l}\text { Corporation } 2 \text { speculating sustainable level of Corporation 1's product in the } \\
\text { case of information asymmetry }\end{array}$ \\
\hline$C_{1}$ & Unit production cost of Corporation 1 \\
\hline$C_{2}$ & Unit production cost of Corporation 2 \\
\hline$C_{1}^{\prime}$ & $\begin{array}{l}\text { Corporation } 2 \text { speculating unit production cost of Corporation } 1 \text { in the case of } \\
\text { information asymmetry }\end{array}$ \\
\hline$E_{1}$ & Unit carbon emission of Corporation 1 \\
\hline$E_{2}$ & Unit carbon emission of Corporation 2 \\
\hline$E_{1}^{\prime}$ & $\begin{array}{l}\text { Corporation } 2 \text { speculating unit carbon emission of Corporation } 1 \text { in the case } \\
\text { of information asymmetry }\end{array}$ \\
\hline$\alpha_{1}$ & Cost factor of Corporation 1 \\
\hline$\alpha_{2}$ & Cost factor of Corporation 2 \\
\hline$\gamma_{1}$ & Carbon emission factor of Corporation 1 \\
\hline$\gamma_{2}$ & Carbon emission factor of Corporation 2 \\
\hline$Q_{1}$ & Product output of Corporation 1 in the case of information asymmetry \\
\hline$Q_{2}$ & Product output of Corporation 2 in the case of information asymmetry \\
\hline$Q_{1}^{\prime}$ & $\begin{array}{l}\text { Corporation } 2 \text { speculating production output of Corporation } 1 \text { in the case of } \\
\text { information asymmetry }\end{array}$ \\
\hline $\bar{Q}_{1}$ & Product output of Corporation 1 in the case of information symmetry \\
\hline $\bar{Q}_{2}$ & Product output of Corporation 2 in the case of information symmetry \\
\hline$P$ & Equilibrium price in the case of information asymmetry \\
\hline $\bar{P}$ & Equilibrium $t$ price in the case of information symmetry \\
\hline$\Pi_{1}$ & The profit of Corporation 1 in the case of information asymmetry \\
\hline$\Pi_{2}$ & The profit of Corporation 2 in the case of information asymmetry \\
\hline$\Pi_{1}^{\prime}$ & $\begin{array}{l}\text { Corporation } 2 \text { speculating profit of Corporation } 1 \text { in the case of information } \\
\text { asymmetry }\end{array}$ \\
\hline $\bar{\Pi}_{1}$ & The profit of Corporation 1 in the case of information symmetry \\
\hline $\bar{\Pi}_{2}$ & The profit of Corporation 2 in the case of information symmetry \\
\hline
\end{tabular}

Table 1. Related Parameters

We also assume that the Corporation 2 is the industry leader, the government requires the Corporation 2 must public its sustainable level, so the sustainable level of Corporation 2 is public for Corporation 1 and the government, the Corporation 1 and government can see the sustainable level of Corporation 2 clearly. Corporation 1 can choose to public to 
its sustainable level, and also can choose not to public its sustainable level. If Corporation 1 public its sustainable level, the information between Corporation 1 and Corporation 2 is symmetry; if Corporation 1 do not public its sustainable level, the information between Corporation 1 and Corporation 2 is asymmetry. Figure 1 shows the model of information asymmetry and information symmetry. In the following section asymmetry information game model and symmetry information game model are proposed to design the sustainable product.

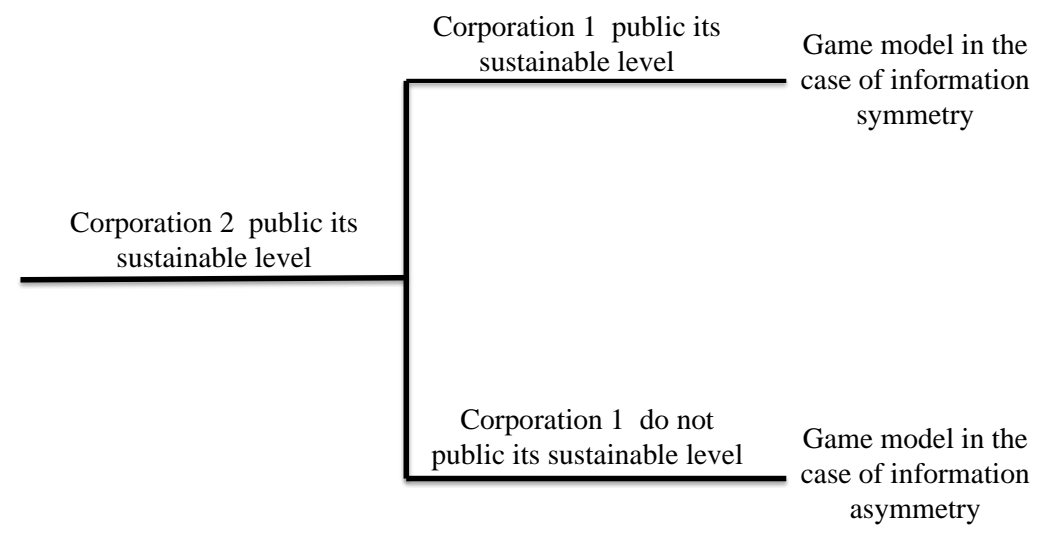

Figure 1. The Model of Information Asymmetry and Information Symmetry

\subsection{Design of Sustainable Product in the Case of Information Asymmetry}

When the carbon tax is imposed by the government, Corporation 1 can choose not to public its sustainable level, so Corporation 2 does not understand the production information about Corporation 1, so the information about Corporation 2 is asymmetry, that is, $\tau_{1}$ is not public for Corporation 2, Corporation 2 does not know the real value of

$\tau_{1}$, Corporation 2 can only speculate the value based on past experience. We assume that Corporation 2 is the industry leader, so the government requires Corporation 2 to disclose its sustainable level of product, so the sustainable level of Corporation 2 is public for Corporation 1, Corporation 1 can know the sustainable level of Corporation 2.

We assume that Corporation 2 speculating sustainable level of Corporation 1's product is $\tau_{1}^{\prime}$, so the game between Corporation 1 and Corporation 2 is static Cournot game in case of information asymmetry. $Q_{1}$ and $Q_{2}$ are the product output of Corporation 1 and Corporation 2, $\Pi_{1}^{\prime}$ is Corporation 2 speculating profit of Corporation $1, \Pi_{1}$ and $\Pi_{2}$ are the profit of Corporation 1 and Corporation 2.

The sustainable level of Corporation $2 \tau_{2}$ is known by both Corporation 1 and Corporation 2, but Corporation 2 does not know the sustainable level of Corporation 1, it can only speculate the sustainable level of Corporation 1 based on past experience. So Corporation 2 can decide the product output $Q_{2}$ through maximizing its profit function $\Pi_{2}$ according equilibrium problems consisting by (3) and (4).

$$
\begin{aligned}
& M A X^{\Pi_{1}^{\prime}=\left(A-Q_{1}-Q_{2}\right) Q_{1}^{\prime}-C_{1}^{\prime} Q_{1}^{\prime}-E_{1}^{\prime} Q_{1}^{\prime} t} \\
& M A X^{\Pi_{2}=\left(A-Q_{1}-Q_{2}\right) Q_{2}-C_{2} Q_{2}-E_{2} Q_{2} t}
\end{aligned}
$$

Solving NASH Equilibrium about above problems is as follows: 


$$
\begin{aligned}
& \frac{\partial \Pi_{1}^{\prime}}{\partial Q_{1}^{\prime}}=\left(A-2 Q_{1}^{\prime}-Q_{2}\right)-C_{1}^{\prime}-E_{1}^{\prime} t=0 \\
& \frac{\partial \Pi_{2}}{\partial Q_{2}}=\left(A-Q_{1}^{\prime}-2 Q_{2}\right)-C_{2}-E_{2} t=0
\end{aligned}
$$

We can get that:

$$
\begin{aligned}
& Q_{1}^{\prime}=\frac{A-2 C_{1}^{\prime}+C_{2}-2 E_{1}^{\prime} t+E_{2} t}{3} \\
& Q_{2}=\frac{A+C_{1}^{\prime}-2 C_{2}+E_{1}^{\prime} t-2 E_{2} t}{3}
\end{aligned}
$$

Corporation 1 has full information about the product design of Corporation 1 and Corporation 2, so Corporation 1 decide the product output $Q_{1}$ through maximizing its profit function $\Pi_{1}$ satisfying the constraint (10).

$$
M A X^{\Pi_{1}=\left(A-Q_{1}-Q_{2}\right) Q_{1}-C_{1} Q_{1}-E_{1} Q_{1} t}
$$

The constraint is

$$
Q_{2}=\frac{A+C_{1}^{\prime}-2 C_{2}+E_{1}^{\prime} t-2 E_{2} t}{3}
$$

Take the derivative of $\Pi_{1}$ with respect to $Q_{1}$

$$
\frac{\partial \Pi_{1}}{\partial Q_{1}}=\left(A-2 Q_{1}-Q_{2}\right)-C_{1}-E_{1} t=0
$$

So we can get:

$$
Q_{1}=\frac{2 . A-C_{1}^{\prime}-3 C_{1}+2 C_{2}-3 E_{1} t-E_{1}^{\prime} t+E_{2} t}{6}
$$

The total product output is:

$$
Q=Q_{1}+Q_{2}=\frac{4 . A+C_{1}^{\prime}-3 C_{1}-2 C_{2}-3 E_{1} t+E_{1}^{\prime} t-2 E_{2} t}{6}
$$

The price is:

$$
P=A-Q_{1}-Q_{1}=\frac{2 A-C_{1}^{\prime}+3 C_{1}+2 C_{2}+3 E_{1} t-E_{1}^{\prime} t+2 E_{2} t}{6}
$$

The profit of Corporation 1 and Corporation 2 are:

$$
\Pi_{1}=\left(\frac{2 A-C_{1}^{\prime}-3 C_{1}+2 C_{2}-3 E_{1} t-E_{1}^{\prime} t+2 E_{2} t}{6}\right)^{2}
$$




$$
\Pi_{2}=\frac{A+C_{1}^{\prime}-2 C_{2}+E_{1}^{\prime} t-2 E_{2} t}{3} \times \frac{2 A-C_{1}^{\prime}+3 C_{1}-4 C_{2}+3 E_{1} t-E_{1}^{\prime} t-4 E_{2} t}{6}
$$

Theorem 1: In the case of information asymmetry, the optimal decisions of Corporation 1 and Corporation 2 is

$$
\left\{\begin{array}{l}
Q_{1}=\frac{2 A-C_{1}^{\prime}-3 C_{1}+2 C_{2}-3 E_{1} t-E_{1}^{\prime} t+E_{2} t}{6} \\
Q_{2}=\frac{A+C_{1}^{\prime}-2 C_{2}+E_{1}^{\prime} t-2 E_{2} t}{3} \\
P=\frac{2 A-C_{1}^{\prime}+3 C_{1}+2 C_{2}+3 E_{1} t-E_{1}^{\prime} t+2 E_{2} t}{6} \\
\Pi_{1}=\left(\frac{2 A-C_{1}^{\prime}-3 C_{1}+2 C_{2}-3 E_{1} t-E_{1}^{\prime} t+2 E_{2} t}{6}\right)^{2} \\
\Pi_{2}=\frac{A+C_{1}^{\prime}-2 C_{2}+E_{1}^{\prime} t-2 E_{2} t}{3} \times \frac{2 A-C_{1}^{\prime}+3 C_{1}-4 C_{2}+3 E_{1} t-E_{1}^{\prime} t-4 E_{2} t}{6}
\end{array}\right.
$$

In the following, the impact of carbon tax on the optimal decision of Corporation 1 and Corporation 2 in the case of information asymmetry is studied.

Theorem 2: When $\tau_{1}^{\prime}>\frac{2 \gamma_{2} \tau_{2}-3 \gamma_{1} \tau_{1}+4 \delta_{1}-2 \delta_{2}}{\gamma_{1}}$, the optimal product output of Corporation 1 increases with the increasing of carbon tax, decreases with the decreasing of carbon tax; when $\tau_{1}^{\prime}<\frac{2 \gamma_{2} \tau_{2}-3 \gamma_{1} \tau_{1}+4 \delta_{1}-2 \delta_{2}}{\gamma_{1}}$, the optimal product output of Corporation 1 decreases with the increasing of carbon tax, increases with the decreasing of carbon tax.

Proof: From Theorem 1, we can get

$$
Q_{1}=\frac{2 A-C_{1}^{\prime}-3 C_{1}+2 C_{2}-3 E_{1} t-E_{1}^{\prime} t+E_{2} t}{6}
$$

$$
\begin{aligned}
& \quad \frac{\partial Q_{1}}{\partial t}=\frac{2 E_{2}-3 E_{1}-E_{1}^{\prime}}{6}=\frac{2\left(-2 \gamma_{2} \tau_{2}+\delta_{2}\right)-3\left(-\gamma_{1} \tau_{1}+\delta_{1}\right)-\left(-\gamma_{1} \tau_{1}^{\prime}+\delta_{1}\right)}{6} \\
& \text { If } \frac{\partial Q_{1}}{\partial t}>0 \text {, so } \tau_{1}^{\prime}>\frac{2 \gamma_{2} \tau_{2}-3 \gamma_{1} \tau_{1}+4 \delta_{1}-2 \delta_{2}}{\gamma_{1}}
\end{aligned}
$$

So when $\tau_{1}^{\prime}>\frac{2 \gamma_{2} \tau_{2}-3 \gamma_{1} \tau_{1}+4 \delta_{1}-2 \delta_{2}}{\gamma_{1}}$, the optimal product output of Corporation 1 increases with the increasing of carbon tax, the optimal product output of Corporation 1 decreases with the decreasing of carbon tax;

The same theory proves that when $\tau_{1}^{\prime}<\frac{2 \gamma_{2} \tau_{2}-3 \gamma_{1} \tau_{1}+4 \delta_{1}-2 \delta_{2}}{\gamma_{1}}$, the optimal product output of Corporation 1 decreases with the increasing of carbon tax, the optimal product output of Corporation 1 increases with the decreasing of carbon tax.

Theorem 3: When $\tau_{1}^{\prime}<\frac{2 \gamma_{2} \tau_{2}+\delta_{1}-2 \delta_{2}}{\gamma_{1}}$, the optimal product output of Corporation 2 increases with the increasing of carbon tax, the optimal product output of Corporation 2 decreases with the decreasing of carbon tax; when $\tau_{1}^{\prime}>\frac{2 \gamma_{2} \tau_{2}+\delta_{1}-2 \delta_{2}}{\gamma_{1}}$, the optimal product output of Corporation 2 decreases with the increasing of carbon tax, the optimal product output of Corporation 1 increases with the decreasing of carbon tax.

Theorem 4: When $\tau_{1}^{\prime}>\frac{3 \gamma_{1} \tau_{1}-2 \delta_{1}+2 \gamma_{2} \tau_{2}-2 \delta_{2}}{\gamma_{1}}$, the equilibrium price in the market increases with the increasing of carbon tax, the equilibrium price in the market decreases with the decreasing of carbon tax; when $\tau_{1}^{\prime}<\frac{3 \gamma_{1} \tau_{1}-2 \delta_{1}+2 \gamma_{2} \tau_{2}-2 \delta_{2}}{\gamma_{1}}$, the equilibrium price 
in the market decreases with the increasing of carbon tax, the equilibrium price in the market increase with the decreasing of carbon tax.

The proof of Theorem 3 and Theorem 4 are the same as Theorem 2.

From above, we can know that Corporation 2 speculating sustainable level of Corporation 1's product is divided into four areas by three points, the three points are $\frac{2 \gamma_{2} \tau_{2}-3 \gamma_{1} \tau_{1}+4 \delta_{1}-2 \delta_{2}}{\gamma_{1}}, \frac{2 \gamma_{2} \tau_{2}+\delta_{1}-2 \delta_{2}}{\gamma_{1}}, \frac{3 \gamma_{1} \tau_{1}-2 \delta_{1}+2 \gamma_{2} \tau_{2}-2 \delta_{2}}{\gamma_{1}}$, next we will sort them.

Because $\frac{2 \gamma_{2} \tau_{2}-3 \gamma_{1} \tau_{1}+4 \delta_{1}-2 \delta_{2}}{\gamma_{1}}-\frac{2 \gamma_{2} \tau_{2}+\delta_{1}-2 \delta_{2}}{\gamma_{1}}=\frac{3 E_{1}}{\gamma_{1}}>0$, so we can know that $\frac{2 \gamma_{2} \tau_{2}-3 \gamma_{1} \tau_{1}+4 \delta_{1}-2 \delta_{2}}{\gamma_{1}}>\frac{2 \gamma_{2} \tau_{2}+\delta_{1}-2 \delta_{2}}{\gamma_{1}}$. And because $\frac{2 \gamma_{2} \tau_{2}+\delta_{1}-2 \delta_{2}}{\gamma_{1}}-\frac{3 \gamma_{1} \tau_{1}-2 \delta_{1}+2 \gamma_{2} \tau_{2}-2 \delta_{2}}{\gamma_{1}}=$ $\frac{3 E_{1}}{\gamma_{1}}>0$, so we can get that $\frac{2 \gamma_{2} \tau_{2}+\delta_{1}-2 \delta_{2}}{\gamma_{1}}>\frac{3 \gamma_{1} \tau_{1}-2 \delta_{1}+2 \gamma_{2} \tau_{2}-2 \delta_{2}}{\gamma_{1}}$. So $\frac{2 \gamma_{2} \tau_{2}-3 \gamma_{1} \tau_{1}+4 \delta_{1}-2 \delta_{2}}{\gamma_{1}}>\frac{2 \gamma_{2} \tau_{2}+\delta_{1}-2 \delta_{2}}{\gamma_{1}}>\frac{3 \gamma_{1} \tau_{1}-2 \delta_{1}+2 \gamma_{2} \tau_{2}-2 \delta_{2}}{\gamma_{1}}$

Corporation 2 speculating sustainable level of Corporation 1's product is divided into (1)(2)(3) four areas by three points which is shown in Figure 2.

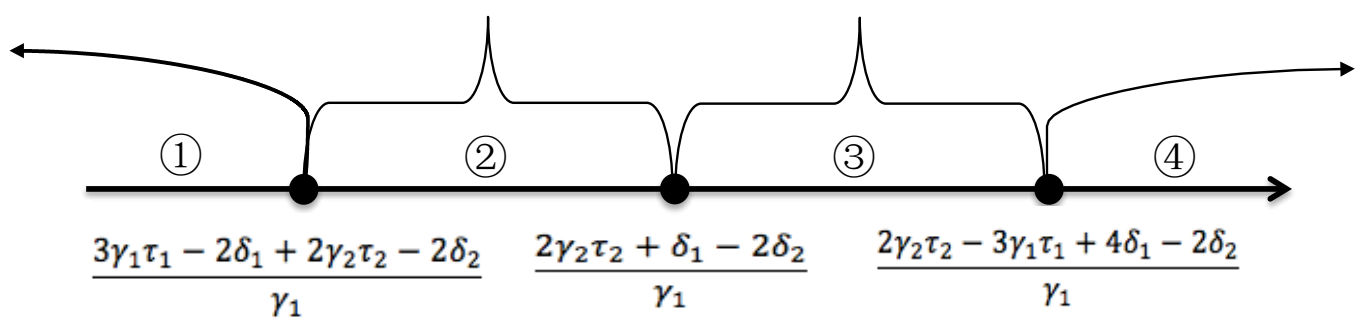

Figure 2. The Area of $\tau_{1}^{\prime}$

The impact of $\tau_{1}^{\prime}$ on the optimal output and equilibrium price of Corporation 1 and Corporation 2 in (1)(2)(3)(4) four areas can be gotten according to Theorem 2, Theorem 3 and Theorem 4.

Area (1): The optimal product output of Corporation 1 decreases with the increasing of carbon tax, increases with the decreasing of carbon tax; The optimal product output of Corporation 2 increases with the increasing of carbon tax, decreases with the decreasing of carbon tax; the equilibrium price decreases with the increasing of carbon tax, increases with the decreasing of carbon tax.

Area (2): The optimal product output of Corporation 1 decreases with the increasing of carbon tax, increases with the decreasing of carbon tax; The optimal product output of Corporation 2 increases with the increasing of carbon tax, decreases with the decreasing of carbon tax; the equilibrium price increases with the increasing of carbon tax, decreases with the decreasing of carbon tax.

Area (3): The optimal product output of Corporation 1 decreases with the increasing of carbon tax, increases with the decreasing of carbon tax; The optimal product output of Corporation 2 decreases with the increasing of carbon tax, increases with the decreasing of carbon tax; the equilibrium price increases with the increasing of carbon tax, decreases with the decreasing of carbon tax.

Area (4): The optimal product output of Corporation 1 increases with the increasing of carbon tax, decreases with the decreasing of carbon tax; The optimal product output of Corporation 2 decreases with the increasing of carbon tax, increases with the decreasing of carbon tax; the equilibrium price increases with the increasing of carbon tax, decreases with the decreasing of carbon tax.

\subsection{Design of Sustainable Product in the Case of Information Symmetry}

In this section, the design of sustainable product in the case of information symmetry is 
discussed. We assume that Corporation 1 and Corporation 2 public their sustainable level of product $\tau_{1}$ and $\tau_{2}$, so Corporation 1 and Corporation 2 can both know the product information of each other. $\bar{\Pi}_{1}$ and $\bar{\Pi}_{2}$ are the profit of Corporation in the case of information symmetry, $\bar{Q}_{1}$ and $\bar{Q}_{2}$ are the optimal product output of Corporation 1 and Corporation 2 in the case of information symmetry, $\bar{P}$ is the equilibrium price in the case of information symmetry. The game model about the design of sustainable product in the case of information symmetry is proposed as follows.

Corporation 1 and Corporation 2 can decide their product output $\bar{Q}_{1}$ and $\bar{Q}_{2}$ through maximizing its profit function $\bar{\Pi}_{1}$ and $\bar{\Pi}_{2}$ according to equation (17) and (18)

$$
\begin{gathered}
M A X^{\bar{\Pi}_{1}=\left(A-\bar{Q}_{1}-\bar{Q}_{2}\right) \bar{Q}_{1}-C_{1} \bar{Q}_{1}-E_{1} \bar{Q}_{1} t} \\
M A X^{\bar{\Pi}_{2}=\left(A-\bar{Q}_{1}-\bar{Q}_{2}\right) \bar{Q}_{2}-C_{1} \bar{Q}_{2}-E_{2} \bar{Q}_{2} t}
\end{gathered}
$$

The reaction function of Corporation 1 and Corporation 2 can be solved by equation (19) and (20)

$$
\begin{aligned}
& \frac{\partial \Pi_{1}}{\partial Q_{2}}=\left(A-2 \underline{Q}_{2}-\underline{Q}_{2}\right)-C_{2}-E_{2} z=0 \\
& \frac{\partial \bar{\Pi}_{2}}{\partial Q_{2}}=\left(A-Q_{1}-2 Q_{2}\right)-C_{2}-E_{2} t=0
\end{aligned}
$$

The reaction function of Corporation 1 and Corporation 2 are:

$$
\begin{aligned}
& Q_{1}=\frac{A-2 C_{1}-2 E_{1} z+C_{2}+E_{z} z}{3} \\
& \Phi_{2}-\frac{A+C_{3}+E_{2} t-2 C_{2}-2 E_{2} t}{3}
\end{aligned}
$$

The total product output is:

$$
\underline{\bar{Q}}=\underline{\Phi}_{1}+\underline{\Phi}_{z}=\frac{2 A-C_{1}-E_{z} z-C_{z}-E_{z} z}{3}
$$

The equilibrium price is:

$$
P=A-\bar{Q}_{1}-\bar{Q}_{2}=\frac{A+C_{1}+E_{1} t+C_{2}+E_{2} t}{3}
$$

So the profit of Corporation 1 and Corporation 2 in the case of information symmetry is:

$$
\begin{aligned}
& \bar{\Pi}_{1}=\left(\frac{A-2 C_{1}-2 E_{1} t+C_{2}+E_{2} t}{3}\right)^{2} \\
& \bar{\Pi}_{2}=\left(\frac{A+C_{1}+E_{1} t-2 C_{2}-2 E_{2} t}{3}\right)^{2}
\end{aligned}
$$

Theorem 5: In the case of information symmetry, the optimal decisions of Corporation 1 and Corporation 2 is 


$$
\left\{\begin{array}{l}
\bar{Q}_{1}=\frac{A-2 C_{1}-2 E_{1} t+C_{2}+E_{2} t}{3} \\
\bar{Q}_{2}=\frac{A+C_{1}+E_{1} t-2 C_{2}-2 E_{2} t}{3} \\
P=A-\bar{Q}_{1}-\bar{Q}_{2}=\frac{A+C_{1}+E_{1} t+C_{2}+E_{2} t}{3} \\
\bar{\Pi}_{1}=\left(\frac{A-2 C_{1}-2 E_{1} t+C_{2}+E_{2} t}{3}\right)^{2} \\
\bar{\Pi}_{2}=\left(\frac{A+C_{1}+E_{1} t-2 C_{2}-2 E_{2} t}{3}\right)^{2}
\end{array}\right.
$$

In the following, the impact of carbon tax on the optimal decision of Corporation 1 and Corporation 2 in the case of information symmetry is studied.

Theorem 6: When $\tau_{1}>\frac{\gamma_{2} \tau_{2}-\delta_{2}+2 \delta_{1}}{2 \gamma_{1}}$, the optimal product output of Corporation 1 increases with the increasing of carbon tax, decreases with the decreasing of carbon tax; when $\tau_{1}<\frac{\gamma_{2} \tau_{2}-\delta_{2}+2 \delta_{1}}{2 \gamma_{1}}$, the optimal product output of Corporation 1 decreases with the increasing of carbon tax, increases with the decreasing of carbon tax.

Theorem 7: When $\tau_{1}<\frac{2 \gamma_{2} \tau_{2}-2 \delta_{2}+\delta_{1}}{\gamma_{1}}$, the optimal product output of Corporation 2 increases with the increasing of carbon tax, decreases with the decreasing of carbon tax; When $\tau_{1}>\frac{2 \gamma_{2} \tau_{2}-2 \delta_{2}+\delta_{1}}{\gamma_{1}}$, the optimal product output of Corporation 2 decreases with the increasing of carbon tax, increases with the decreasing of carbon tax.

Theorem 8: The equilibrium price in the market increases with the increasing of carbon tax, decreases with the decreasing of carbon tax.

The proof of Theorem 6, Theorem 7 and Theorem 8 are the same as Theorem 2.

From above, we can know that sustainable level of Corporation 1's product is divided into three areas by two points, the two points are $\frac{\gamma_{2} \tau_{2}-\delta_{2}+2 \delta_{1}}{2 \gamma_{1}}, \frac{2 \gamma_{2} \tau_{2}-2 \delta_{2}+\delta_{1}}{\gamma_{1}}$, next we will sort them.

Because $\frac{\gamma_{2} \tau_{2}-\delta_{2}+2 \delta_{1}}{2 \gamma_{1}}-\frac{2 \gamma_{2} \tau_{2}-2 \delta_{2}+\delta_{1}}{\gamma_{1}}=\frac{-3 \gamma_{2} \tau_{2}+3 \delta_{2}}{2 \gamma_{1}}=\frac{3 E_{2}}{2 \gamma_{1}}>0 \quad, \quad$ so $\quad \frac{\gamma_{2} \tau_{2}-\delta_{2}+2 \delta_{1}}{2 \gamma_{1}}>$ $\frac{2 \gamma_{2} \tau_{2}-2 \delta_{2}+\delta_{1}}{\gamma_{1}}$. The sustainable level of Corporation 1's product is divided into (1)(2)(3) three areas by two points which is shown in Figure 3.

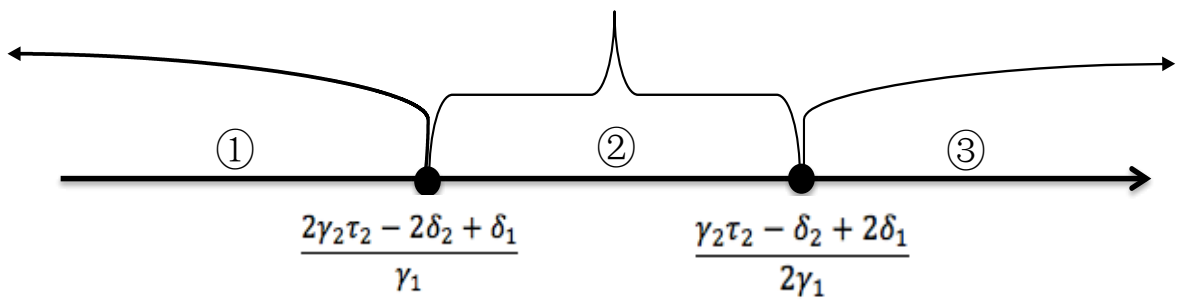

Figure 3. The Area of $\tau_{1}$

The impact of $\tau_{1}$ on the optimal output and equilibrium price of Corporation 1 and Corporation 2 in (1)(2)(3) three areas can be gotten according to Theorem 6, Theorem 7 and Theorem 8.

Area (1): The optimal product output of Corporation 1 decreases with the increasing of carbon tax, increases with the decreasing of carbon tax; The optimal product output of Corporation 2 increases with the increasing of carbon tax, decreases with the decreasing 
of carbon tax; the equilibrium price increases with the increasing of carbon tax, decreases with the decreasing of carbon tax.

Area (2): The optimal product output of Corporation 1 decreases with the increasing of carbon tax, increases with the decreasing of carbon tax; The optimal product output of Corporation 2 decreases with the increasing of carbon tax, increases with the decreasing of carbon tax; the equilibrium price increases with the increasing of carbon tax, decreases with the decreasing of carbon tax.

Area (3): The optimal product output of Corporation 1 increases with the increasing of carbon tax, decreases with the decreasing of carbon tax; The optimal product output of Corporation 2 decreases with the increasing of carbon tax, increases with the decreasing of carbon tax; the equilibrium price increases with the increasing of carbon tax, decreases with the decreasing of carbon tax.

\section{Comparing and Analyzing}

In this section, the impact of information symmetry and information asymmetry on the optimal product output, the equilibrium price and profit is discussed.

Theorem 9: If $\alpha_{1}>\gamma_{1} t$, when $\tau_{1}^{\prime}<\tau_{1}$, that $Q_{1}>\bar{Q}_{1}$, when $\tau_{1}^{\prime}>\tau_{1}$, that $Q_{1}<\bar{Q}_{1}$; If $\alpha_{1}<\gamma_{1} t$, when $\tau_{1}^{\prime}<\tau_{1}$, that $Q_{1}<\bar{Q}_{1}$, when $\tau_{1}^{\prime}>\tau_{1}$, that $Q_{1}>\bar{Q}_{1}$

Proof:

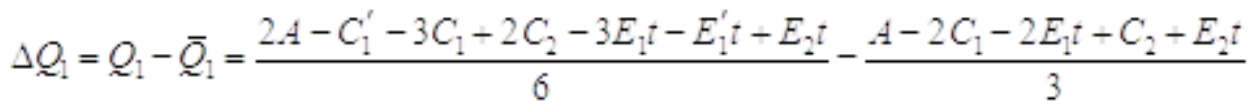

$$
=\frac{C_{1}-C_{1}^{\prime}+E_{1} t-E_{1}^{\prime} t}{6}=\frac{\left(\tau_{1}-\tau_{1}^{\prime}\right)\left(\alpha_{1}-\gamma_{1} t\right)}{6}
$$

If $\alpha_{1}>\gamma_{1}$ t, when $\tau_{1}^{\prime}<\tau_{1}$, so $\Delta Q_{1}>0$, that is $\mathrm{Q}_{1}>\overline{\mathrm{Q}}_{1}$

If $\alpha_{1}>\gamma_{1}$ t, when $\tau_{1}^{\prime}>\tau_{1}$, so $\Delta Q_{1}<0$, that is $Q_{1}<\bar{Q}_{1}$

If $\alpha_{1}<\gamma_{1}$ t, when $\tau_{1}^{\prime}<\tau_{1}$, so $\Delta Q_{1}<0$, that is $Q_{1}<\bar{Q}_{1}$

If $\alpha_{1}<\gamma_{1}$ t, when $\tau_{1}^{\prime}>\tau_{1}$, so $\Delta Q_{1}>0$, that is $Q_{1}>\bar{Q}_{1}$

From Theorem 9 we can know that if the cost factor is greater than the product of carbon emission factor and carbon tax of Corporation 1, when Corporation 2 speculating sustainable level of Corporation 1's product is less than the real sustainable level of Corporation 1's product, the optimal product output in the case of information asymmetry is greater than information symmetry; when Corporation 2 speculating sustainable level of Corporation 1's product is greater than the real sustainable level of Corporation 1's product, the optimal product output in the case of information asymmetry is less than information symmetry. If the cost factor is less than the product of carbon emission factor and carbon tax of Corporation 1, when Corporation 2 speculating sustainable level of Corporation 1's product is less than the real sustainable level of Corporation 1's product, the optimal product output in the case of information asymmetry is less than information symmetry; when Corporation 2 speculating sustainable level of Corporation 1's product is greater than the real sustainable level of Corporation 1's product, the optimal product output in the case of information asymmetry is greater than information symmetry.

Theorem 10: If $\alpha_{1}>\gamma_{1}$ t, when $\tau_{1}^{\prime}<\tau_{1}$, that $\mathrm{P}<\overline{\mathrm{P}}$, when $\tau_{1}^{\prime}>\tau_{1}$, that $\mathrm{P}>\overline{\mathrm{P}}$; If $\alpha_{1}<\gamma_{1}$ t, when $\tau_{1}^{\prime}<\tau_{1}$, that $\mathrm{P}>\overline{\mathrm{P}}$, when $\tau_{1}^{\prime}>\tau_{1}$, that $\mathrm{P}<\overline{\mathrm{P}}$

Proof:

$$
\Delta P=P-P=\frac{2 A-C_{1}^{\prime}+3 C_{1}+2 C_{2}+3 E_{1} t-E_{1}^{\prime} t+2 E_{2} t}{6}-\frac{A+C_{1}+E_{1} t+C_{2}+E_{2} t}{3}
$$

$$
\begin{aligned}
& =\frac{C_{1}-C_{1}^{\prime}+E_{1} t-E_{1}^{\prime} t}{6}=\frac{\left(\tau_{1}-\tau_{1}^{\prime}\right)\left(\alpha_{1}-\gamma_{1} t\right)}{6} \\
& \text { If } \alpha_{1}>\gamma_{1} t \text {, when } \tau_{1}^{\prime}<\tau_{1} \text {, so } \Delta \mathrm{P}<0 \text {, that is } P<\overline{\mathrm{P}}
\end{aligned}
$$




$$
\begin{aligned}
& \text { If } \alpha_{1}>\gamma_{1} t \text {, when } \tau_{1}^{\prime}>\tau_{1} \text {, so } \Delta \mathrm{P}>0 \text {, that is } P>\overline{\mathrm{P}} \\
& \text { If } \alpha_{1}<\gamma_{1} t \text {, when } \tau_{1}^{\prime}<\tau_{1} \text {, so } \Delta \mathrm{P}>0 \text {, that is } P>\overline{\mathrm{P}} \\
& \text { If } \alpha_{1}<\gamma_{1} t \text {, when } \tau_{1}^{\prime}>\tau_{1} \text {, so } \Delta \mathrm{P}<0 \text {, that is } P<\overline{\mathrm{P}}
\end{aligned}
$$

From Theorem 10 we can know that if the cost factor is greater than the product of carbon emission factor and carbon tax of Corporation 1, when Corporation 2 speculating sustainable level of Corporation 1's product is less than the real sustainable level of Corporation 1's product, equilibrium price in the case of information asymmetry is less than information symmetry; when Corporation 2 speculating sustainable level of Corporation 1's product is greater than the real sustainable level of Corporation 1's product, equilibrium price in the case of information asymmetry is greater than information symmetry. If the cost factor is less than the product of carbon emission factor and carbon tax of Corporation 1, when Corporation 2 speculating sustainable level of Corporation 1's product is less than the real sustainable level of Corporation 1's product, equilibrium price in the case of information asymmetry is greater than information symmetry; when Corporation 2 speculating sustainable level of Corporation 1's product is greater than the real sustainable level of Corporation 1's product, equilibrium price in the case of information asymmetry is less than information symmetry.

Theorem 11: If $\alpha_{1}>\gamma_{1} t$, when $\tau_{1}^{\prime}>\tau_{1}$, that $\Pi_{1}>\bar{\Pi}_{1}$, when $\tau_{1}^{\prime}<\tau_{1}$, that $\Pi_{1}<$ $\bar{\Pi}_{1}$; if $\alpha_{1}<\gamma_{1} t$, when $\tau_{1}^{\prime}>\tau_{1}$, that $\Pi_{1}<\bar{\Pi}_{1}$, when $\tau_{1}^{\prime}<\tau_{1}$, that $\Pi_{1}>\bar{\Pi}_{1}$.

Proof: The profit in the case of information asymmetry $\Pi_{1}$ equals to

$$
\begin{aligned}
\Pi_{1} & =\left(\frac{2 A-C_{1}^{\prime}-3 C_{1}+2 C_{2}-3 E_{1} t-E_{1}^{\prime} t+2 E_{2} t}{6}\right)^{2}=\left(\frac{A-2 C_{1}-2 E_{1} t+C_{2}+E_{2} t}{3}+\frac{C_{1}-C_{1}^{\prime}+E_{1} t-E_{1}^{\prime} t}{6}\right)^{2} \\
& =\left(\frac{A-2 C_{1}-2 E_{1} t+C_{2}+E_{2} t}{3}+\frac{\left(\tau_{1}-\tau_{1}^{\prime}\right)\left(\alpha_{1}-\gamma_{1} t\right)}{6}\right)^{2}
\end{aligned}
$$

The profit in the case of information symmetry $\bar{\Pi}_{1}$ equals to

$$
\begin{aligned}
& \bar{\Pi}_{1}=\left(\frac{A-2 C_{1}-2 E_{1} t+C_{2}+E_{2} t}{3}\right)^{2} \\
& \text { If } \alpha_{1}>\gamma_{1} t \text {, when } \tau_{1}^{\prime}>\tau_{1} \text {, that } \Pi_{1}>\bar{\Pi}_{1} \\
& \text { If } \alpha_{1}>\gamma_{1} t \text {, when } \tau_{1}^{\prime}<\tau_{1} \text {, that } \Pi_{1}<\bar{\Pi}_{1} \\
& \text { If } \alpha_{1}<\gamma_{1} t \text {, when } \tau_{1}^{\prime}>\tau_{1} \text {, that } \Pi_{1}<\bar{\Pi}_{1} \\
& \text { If } \alpha_{1}<\gamma_{1} t \text {, when } \tau_{1}^{\prime}<\tau_{1} \text {, that } \Pi_{1}>\bar{\Pi}_{1}
\end{aligned}
$$

From Theorem 11 we can know that if the cost factor is greater than the product of carbon emission factor and carbon tax of Corporation 1, when Corporation 2 speculating sustainable level of Corporation 1's product is greater than the real sustainable level of Corporation 1's product, the profit of Corporation 1 in the case of information asymmetry is greater than information symmetry, so Corporation 1 should not public its sustainable level; when Corporation 2 speculating sustainable level of Corporation 1's product is less than the real sustainable level of Corporation 1's product, the profit of Corporation 1 in the case of information asymmetry is less than information symmetry, so Corporation 1 should public its sustainable level. If the cost factor is greater than the product of carbon emission factor and carbon tax of Corporation 1, when Corporation 2 speculating sustainable level of Corporation 1's product is greater than the real sustainable level of Corporation 1's product, the profit of Corporation 1 in the case of information asymmetry is less than information symmetry, so Corporation 1 should public its sustainable level. When Corporation 2 speculating sustainable level of Corporation 1's product is less than the real sustainable level of Corporation 1's product, the profit of Corporation 1 in the case of information asymmetry is greater than information symmetry, so Corporation 1 
should not public its sustainable level.

\section{Conclusions}

In this paper, two game models in the case of information asymmetry and information symmetry are developed for the design of sustainable product. We also analyze the impact of information symmetry and information asymmetry on the optimal product output, the equilibrium price and profit in this paper. A series of conclusions is obtained as follows.

Firstly, in the case of information asymmetry, with the increasing or decreasing of carbon tax, the optimal product output, the equilibrium of Corporation 1 and Corporation should increase or decrease according to carbon emission factor of Corporation 1 and Corporation 2, carbon emission intercept of Corporation 1 and Corporation 2, Corporation 2 speculating sustainable level of Corporation 1's product and the sustainable level of Corporation 2.

Secondly, in the case of information asymmetry, with the increasing or decreasing of carbon tax, the optimal product output, the equilibrium of Corporation 1 and Corporation should increase or decrease according to carbon emission factor of Corporation 1 and Corporation 2, carbon emission intercept of Corporation 1 and Corporation 2, the sustainable level of Corporation1 and Corporation 2.

Thirdly, if the cost factor is greater than the product of carbon emission factor and carbon tax of Corporation 1, when Corporation 2 speculating sustainable level of Corporation 1's product is greater than the real sustainable level of Corporation 1's product, so Corporation 1 should not public its sustainable level; when Corporation 2 speculating sustainable level of Corporation 1's product is less than the real sustainable level of Corporation 1's product, so Corporation 1 should public its sustainable level. If the cost factor is greater than the product of carbon emission factor and carbon tax of Corporation 1, when Corporation 2 speculating sustainable level of Corporation 1's product is greater than the real sustainable level of Corporation 1's product, so Corporation 1 should public its sustainable level. When Corporation 2 speculating sustainable level of Corporation 1's product is less than the real sustainable level of Corporation 1's product, Corporation 1 should not public its sustainable level.

\section{References}

[1] C. Bai and J. Sarkis, "Green supplier development: Analytical evaluation using rough set theory", Journal of Cleaner Production, vol. 18, no. 12, (2010), pp. 1200-1210.

[2] C. Chen, J. Zhu, J. Y. Yu and H. Noori, "A new methodology for evaluating sustainable product design performance with two-stage network data envelopment analysis", European Journal of Operational Research, vol. 221, no. 2, (2012), pp. 348-359.

[3] H. B. Duan, L. Zhu and Y. Fan, "Optimal carbon taxes in carbon-constrained China: A logistic-induced energy economic hybrid model", Energy, vol. 69, (2014), pp. 345-356.

[4] W. D. Nordhaus, "Greenhouse economics: count before you leap", The Economist, vol. 316, no. 7662, (1990), pp. 19-22.

[5] T. Nakata and A. Lamont, "Analysis of the impacts of carbon taxes on energy systems in Japan", Energy Policy, vol. 29, no. 2, (2001), pp. 159-166.

[6] H. B. Duan, L. Zhu and Y. Fan, "Optimal carbon taxes in carbon-constrained China: A logistic-induced energy economic hybrid model”, Energy, vol. 69, (2014), pp. 345-356.

[7] D. Pujari, K. Peattie and G. Wright, "Organizational antecedents of environmental responsiveness in industrial new product development", Industrial Marketing Management, vol. 33, no. 5, (2004), pp. 381-391.

[8] K. M. Rehfeld, K. Rennings and A. Ziegler, "Integrated product policy and environmental product innovations: an empirical analysis", Ecological Economics, vol. 61, no. 1, (2007), pp. 91-100.

[9] C. Chen, "Design for the environment: a quality-based model for green product development", Management Science, vol. 47, no. 2, (2001), pp. 250-263.

[10] P. Calcott and M. Walls, "Can downstream waste disposal policies encourage upstream design for environment?", American Economic Review, vol. 90, no. 2, (2000), pp. 233-237.

[11] A. Atasu and G. C. Souza, "How Does Product Recovery Affect Quality Choice?", Working Paper, George Institute of Technology, Atlanta, (2010). 
[12] D. Fullerton and W. Wu, "Policies for green design", Journal of Environmental Economics and Management, vol. 36, (1998), pp. 131-148.

[13] A. Atasu, M. Sarvary and L. N. Van Wassenhove, "Remanufacturing as a marketing strategy", Management Science, vol. 54, no. 10, (2008), pp. 1731-1747.

[14] R. B. Handfield, S. A. Melnyk, R. J. Calantone and S. Curkovic, "Integrating Environmental concerns into the design process: the gap between theory and practice", IEEE Transactions on Engineering Management, vol. 48,no. 2, (2001), pp. 189-208.

[15] T. E. Graedel and B. R. Allenby, "Industrial ecology and sustainable engineering", (2010).

[16] J. Fiksel, "Design for environment: A guide to sustainable product development: Eco-efficient product development", (2009).

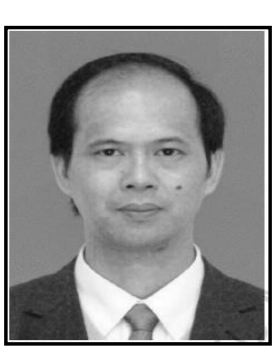

\section{Authors}

Shuihua Han, a professor of information system, in School of Management at Xiamen University. His research interests are in Business intelligent, Supply chain Management, and RFID technology.

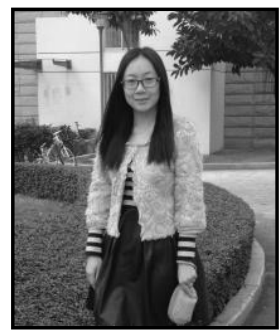

Yue Jiang, a PhD student at Xiamen University. She follows professor Shuihua Han on the research fields of supply chain management, operations management and production planning and control. She has a master degree in Corporation management from Shenyang University of Technology. 
International Journal of $u-$ and $\mathrm{e}-$ Service, Science and Technology Vol.9, No. 7 (2016) 